\title{
Comparative Evaluation of Direct Disposal and Pyro-SFR Nuclear Fuel Cycle Alternatives Using Multi Criteria Decision Making in Korea
}

\author{
Sungki Kim *, Jin-Seop Kim and Dong-Keun Cho
}

Citation: Kim, S.; Kim, J.-S.; Cho, D.-K. Comparative Evaluation of Direct Disposal and Pyro-SFR Nuclear Fuel Cycle Alternatives Using Multi Criteria Decision Making in Korea. Energies 2021, 14, 3590. https://doi.org/10.3390/en14123590

Academic Editors: Arturo Buscarino and Dan Gabriel Cacuci

Received: 6 May 2021

Accepted: 11 June 2021

Published: 16 June 2021

Publisher's Note: MDPI stays neutral with regard to jurisdictional claims in published maps and institutional affiliations.

Copyright: (C) 2021 by the authors. Licensee MDPI, Basel, Switzerland. This article is an open access article distributed under the terms and conditions of the Creative Commons Attribution (CC BY) license (https:// creativecommons.org/licenses/by/ $4.0 /)$.
Korea Atomic Energy Research Institute, 1045 Daedeokdaero, Yuseong-gu, Daejeon 305-353, Korea; kjs@kaeri.re.kr (J.-S.K.); dkcho@kaeri.re.kr (D.-K.C.)

* Correspondence: sgkim1@kaeri.re.kr; Tel.: +82-42-868-8892; Fax: +82-42-868-8679

\begin{abstract}
The Korean government is currently evaluating two alternatives, direct disposal and pyroprocessing, for the disposal of spent nuclear fuel. This paper presents the ranking results of comparing and evaluating direct disposal and pyro-SFR fuel cycle alternatives using multi-criteria decision-making methods such as AHP, TOPSIS, and PROMETHEE. In considering the various evaluation criteria involved in these two alternatives, we aimed to determine the optimal choice in terms of the economic and social conditions of Korea. The evaluation criteria considered were safety, resource availability, environmental impact, economics, nuclear proliferation resistance, and public acceptance. The results show that the pyro-SFR fuel cycle alternative is more advantageous than direct disposal in the AHP and TOPSIS methods, whereas direct disposal is more advantageous in the PROMETHEE method because the ranking is reversed. TOPSIS assigns the ideal value and the most negative value among the input values to each criterion as a parameter reflecting the concept of distance between the best alternative and the worst alternative. In contrast, the PROMETHEE method first selects the preference function including the preference threshold, and calculates the preferred outflow and the preferred inflow for the detailed evaluation indicators. Therefore, differences exist in the methodologies of multi-criteria decision making. Nonetheless, the analysis results of the back-end fuel cycle option can greatly contribute to establishing a nuclear policy for the back-end nuclear fuel cycle, and these efforts will enable sustainable nuclear power generation.
\end{abstract}

Keywords: nuclear fuel cycle; alternatives; multi-criteria decision making; evaluation criteria; evaluation index(indicator); weight; direct disposal; Pyro-SFR fuel cycle; economics; PROMETHEE

\section{Introduction}

Korea is currently developing pyroprocessing and direct disposal as methods of managing spent fuel. Therefore, it is necessary to analyze which of the two methods is more efficient and economical. This is because the temporary storage for spent fuel at the nuclear power plant sites in Korea is expected to be saturated by 2024 .

In general, nuclear fuel cycle alternatives are evaluated using a variety of criteria. For example, technology and safety, resource utilization, environmental friendliness, nuclear proliferation resistance, and economics may be used as criteria for evaluating nuclear fuel cycle alternatives [1]. The weight of various criteria can be a very important factor for the selection of the desired nuclear fuel cycle, and may vary according to the social and economic environment of each country. Hence, the weight should be derived using scientific and systematic methods when determining the preference of nuclear fuel cycle alternatives $[2,3]$.

A representative group of non-nuclear experts could be residents living around nuclear power plants. These residents have a greater interest in nuclear facilities than residents of other regions. Therefore, it is advisable to include the residents nearby nuclear power plants as non-expert groups. That is, all survey groups should have a good understanding 
of nuclear power and the residents should be included in the questionnaire to produce reliable weights.

Nuclear fuel cycle alternative evaluation methods include Analytic Hierarchy Process (AHP), Technique for Order Preference by Similarity to Ideal Solution (TOPSIS), and Preference Ranking Organization Method for Enrichment Evaluations (PROMETHEE) [4-7]. The research methodology of this study can be summarized as follows. First, direct disposal and pyro-SFR nuclear fuel cycles were considered as nuclear fuel cycle alternatives, because these two alternatives are currently being researched with government funding and are likely to be used in the future. Second, the weighting of various evaluation criteria for evaluating nuclear fuel cycle alternatives was based on the rank weighting method derived from a survey conducted by Korea Research Co., Ltd. (Seoul, Korea) in 2012 [8]. The survey was conducted through direct interviews with the survey respondents. Third, the multicriteria decision-making method was adopted to evaluate nuclear fuel cycle alternatives. This evaluation method is commonly used in industrial engineering to evaluate systems with many criteria and indicators [9].

AHP has particular application in group decision making [10], and is now used around the world in a wide variety of decision situations, in fields such as government, business, industry, healthcare, education, and energy [11]. The AHP method was pioneered by Professor Saaty in the 1970s, and remains the standard method for this application. Decision making involves ranking alternatives in terms of criteria or attributes of those alternatives.

It is an axiom of some decision theories that, when new alternatives are added to a decision problem, the ranking of the old alternatives must not change; that is, "rank reversal" does not arise.

The evaluation criteria and weights are first described in detail in Section 2. In addition, Section 3 describes the multi-criteria decision-making method (MCDM). The calculation results of MCDM are presented in Section 4. Finally, conclusions are drawn from the results of MCDM.

\section{Materials and Methods}

\subsection{Evaluation Criteria}

In this study, three methods-AHP, TOPSIS, and PROMETHEE-were used together to undertake the comparative evaluation of each option $[12,13]$. This multi-criteria decisionmaking method requires evaluation criteria and associated weights [14]. The necessary evaluation criteria were identified and are shown in Table 1 [15].

Table 1. Evaluation criteria of the multi-criteria decision making (MCDM) model.

\begin{tabular}{|c|c|c|}
\hline \multicolumn{3}{|c|}{ Evaluation Criteria } \\
\hline \multicolumn{2}{|c|}{ Survey Results } & MCDM \\
\hline \multirow{2}{*}{ Technology } & $\rightarrow$ & Safety \\
\hline & $\rightarrow$ & Resource utilization \\
\hline Environmental impact & $\rightarrow$ & Environmental impact \\
\hline Economic & $\rightarrow$ & Economic \\
\hline Sociality & $\rightarrow$ & Public acceptance \\
\hline Institution & $\rightarrow$ & Proliferation resistance \\
\hline
\end{tabular}

Resource utilization was included in the evaluation criteria because one of the main purposes of pyroprocessing is to recover TRU as a raw material of SFR fuel from the recycled spent fuel [16]. Environmental impacts were included because the direct disposal method is closely related to the human ecosystem as spent fuel is disposed of in deep rock masses. Economic feasibility was also included in the evaluation criteria because it must be reviewed in relation to the project [17]. In recent years, public acceptance has been considered as an evaluation criterion in all large-scale projects carried out by the state, 
because the advantages and disadvantages of the project have emerged as an important factor for the promotion of the project [18]. State-led projects can be an important factor in nuclear fuel cycle alternatives because only projects approved by the majority of people can proceed smoothly [19-21]. Therefore, public acceptance can be an important evaluation criterion [22]. Finally, nuclear proliferation resistance was included in the nuclear fuel cycle evaluation criteria because it is an internationally and domestically sensitive item in relation to the situation on the Korean peninsula [23].

Evaluation criteria of the multi-criteria decision-making model were subdivided into detailed evaluation indicators, as shown in Figure 1. These detailed indicators are closely related to the direct disposal and pyro-SFR nuclear fuel cycle alternatives. To evaluate each alternative correctly, the detailed indicators should include the important attributes of the evaluation criteria. The attributes of the detailed indicators can be expressed quantitatively or qualitatively. Finally, the six evaluation criteria consisted of the detailed evaluation indicators shown in Table 2.

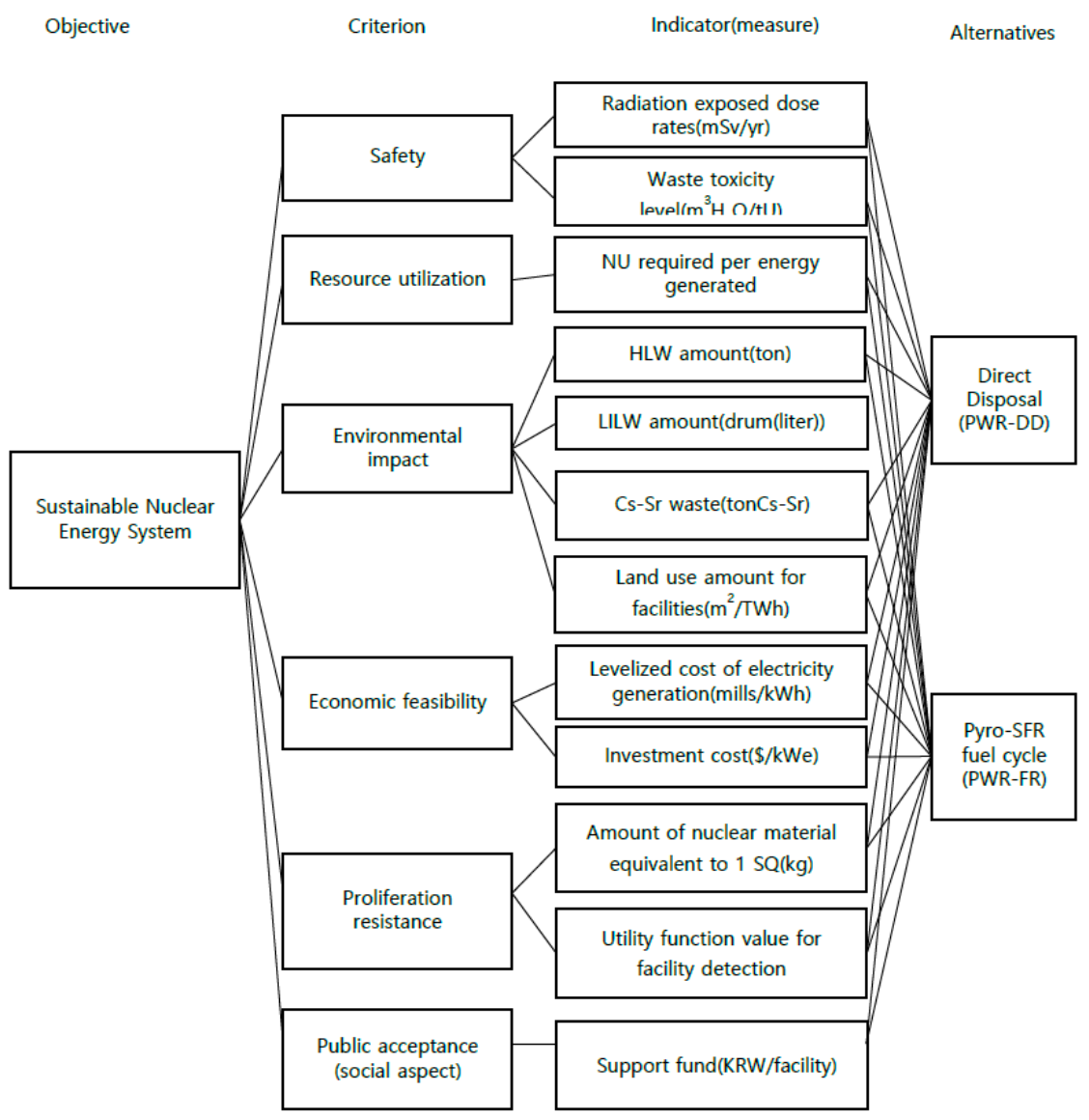

Figure 1. Evaluation criteria and evaluation index for two alternatives.

For the safety indicators, we referred to the deterministic safety assessment of a wet reprocessing facility and estimated the exposure dose to the public around the pyro facility as $5 \mathrm{mSv}$ /year. For reference, the usual dose rate target is $50 \mu \mathrm{Sv}$ /year and the mortality risk of the probabilistic safety assessment is $10^{-6}$ deaths/year. In addition, the safety assessment index of a high-level radioactive waste disposal repository related to direct disposal was assumed to be $10 \mathrm{mSv} /$ year [24]. This is because, under the notification of the Nuclear Safety Commission in Korea, the expected exposure dose rate under a single scenario, such as natural phenomena and human invasion, is unlikely to exceed 10 milliSievert(mSv)/year. 
Table 2. Evaluation criteria and evaluation index.

\begin{tabular}{|c|c|c|}
\hline Evaluation Criteria & Evaluation Index & Unit \\
\hline \multirow{2}{*}{$\begin{array}{c}\text { Safety } \\
\text { (2 evaluation index) }\end{array}$} & (1) Radiation exposed dose rates & $\mathrm{mSv} /$ year \\
\hline & (2) Waste toxicity level & $\mathrm{m}^{3} \mathrm{H}_{2} \mathrm{O} / \mathrm{GWe}$ \\
\hline $\begin{array}{l}\text { Resource utilization } \\
\text { (1 evaluation index) }\end{array}$ & (1) Natural uranium consumption & $\mathrm{tU} / \mathrm{TWh}$ \\
\hline \multirow{4}{*}{$\begin{array}{l}\text { Environmental elements } \\
\quad(4 \text { evaluation index })\end{array}$} & (1) Amounts of high-level waste & Ton/TWh \\
\hline & (2) Amounts of LILW waste & $\mathrm{m}^{3} / \mathrm{TWh}$ \\
\hline & (3) Amounts of Cs/Sr waste & $\mathrm{kg}$ \\
\hline & (4) Land use & $\mathrm{m}^{2} / \mathrm{TWh}$ \\
\hline \multirow{2}{*}{$\begin{array}{c}\text { Economic } \\
\text { (2 evaluation index) }\end{array}$} & (1) Levelized cost* & Mills/kWh \\
\hline & (2) Capital investment cost & $\$ / \mathrm{kWe}$ \\
\hline \multirow{2}{*}{$\begin{array}{l}\text { Proliferation resistance } \\
\text { (2 evaluation index) }\end{array}$} & (1) Nuclear material for $1 \mathrm{SQ}$ (Significant Quantity) equivalents & $\mathrm{Kg}$ \\
\hline & (2) The qualitative measure of the worth of utility function for facility inspection & N/A \\
\hline $\begin{array}{l}\text { Public acceptance } \\
\text { (1 evaluation index) }\end{array}$ & (1) Supporting fund for facility construction & Hundred million won (KRW) \\
\hline
\end{tabular}

${ }^{*}$ Levelized cost of energy (LCOE) is a measure of the average net present cost of electricity generation for a generating plant over its lifetime.

In recent years, public acceptance has become an important factor in determining nuclear sustainability. Therefore, in this study, the evaluation index of public acceptance was used based on the Willingness to Pay (WTP) method used in the survey for quantitative evaluation. We used a questionnaire to ask how much money the state should pay local residents to build the nuclear facility. The more subsidies to local residents, the lower the public acceptance. If there is a large difference in the willingness to pay for the high-level waste repository and the Pyro facility, it can be judged that there is a large difference in the perceived risk of respondents between the high-level waste repository and the pyro facility. The perceived risk equates with the respondent's awareness of the safety for nuclear facilities.

In addition, the evaluation index of nuclear proliferation resistance was based on the utility function value and the amount of nuclear material corresponding to $1 \mathrm{SQ}$. For example, in the case of direct disposal, the evaluation index was used to estimate how much spent fuel must be processed to produce $8 \mathrm{~kg}$ of $\mathrm{Pu}[25,26]$.

\subsection{Weight}

As the number of evaluation criteria increases it becomes more difficult to determine the ranking. Therefore, if the number of evaluation criteria is large, a scientific and systematic weighting method is required [27]. One such weighting method is rank weighting. That is, the method calculates the relative importance order of the evaluation criteria through a questionnaire, and then calculates the weight using the order value. For example, the rank-sum weight is a simple but reasonable way to calculate the weight from rank values obtained from expert and public surveys. Another possible method for determining the importance of an evaluation criterion is to take the inverse of its rank. By setting the sum of the inverses as the denominator and calculating the reciprocal of the rank for the corresponding evaluation criteria, the weight can be obtained. This is called the rank-reciprocal weight [27], which is an efficient way to easily calculate reasonable weights using survey values.

Table 3 shows the results of calculating the rank inverse for the evaluation criteria of this study, using the priority of the criteria derived from the survey. As shown in Table 3, the weight of the safety evaluation criterion was set to be the highest. 
Table 3. Rank-reciprocal weight of evaluation index [8].

\begin{tabular}{|c|c|c|}
\hline Evaluation Criteria & Sub-Criteria & Weighting \\
\hline \multirow{2}{*}{ Safety } & Radiation exposed dose rates(mSv/year) & 0.11 \\
\hline & Waste toxicity level $\left(\mathrm{m}^{3} \mathrm{H}_{2} \mathrm{O} / \mathrm{GWe}\right)$ & 0.11 \\
\hline Resource utilization & Natural Uranium (NU) required per energy generated (tU/TWh) & 0.22 \\
\hline \multirow{4}{*}{ Environmental impact } & HLW (ton/TWh) & 0.055 \\
\hline & LILW Volume ( $\left.\mathrm{m}^{3} / \mathrm{TWh}\right)$ & 0.055 \\
\hline & Cs/Sr waste $(\mathrm{kg})$ & 0.055 \\
\hline & Land Use for HLW disposal per energy generated (m²/TWh) & 0.055 \\
\hline \multirow{2}{*}{ Economic } & Levelized cost of Electricity Generation (mills/kWh) & 0.075 \\
\hline & Capital investment cost $(\$ / \mathrm{kWe})$ & 0.075 \\
\hline \multirow{2}{*}{ Proliferation resistance } & Amount of nuclear material for 1 Significant Quantity (SQ) equivalents $(\mathrm{kg})$ & 0.045 \\
\hline & The value of utility function for facility inspection & 0.045 \\
\hline Public acceptance & Supporting fund (unit: hundred million won(KRW)/facility) & 0.10 \\
\hline
\end{tabular}

\subsection{Material Flow Information and Assumptions}

The fundamental task for nuclear fuel cycle analysis is to analyze nuclear material flows [28]. This is because basic information, such as waste generation and generation costs, are derived from the flow of nuclear materials.

In general, based on the economic growth rate of the country, Nuclear Fuel Cycle (NFC) software developed at Korea Atomic Energy Institute (KAERI) can be used to calculate the required fuel by predicting the future power generation. In addition, knowing the amount of spent fuel according to the required fuel, the amount of nuclear material generated in the front-end fuel cycle process can be obtained. That is, the material flow of each unit process in the front-end and back-end fuel cycle stages can be calculated by examining the loss rate of each unit process.

Considering that the total capacity of 20 pressurized-water reactors (PWRs) operating in Korea is 19.75 GWe, the PWR capacity of both the direct disposal cycle and the pyroSFR fuel cycle alternatives is fixed at $20 \mathrm{GWe}$. A solution that satisfies the mass balance including material loss in the pyro-SFR recirculation flow was found to result in a need for a sodium-cooled fast reactor (SFR) of 9.7 GWe at 20 GWe of PWR generation capacity. When the oxide fuel loading and the metal fuel loading according to the light-water reactor and the SFR capacity are determined, the mass flows of the front-end fuel cycle and the back-end fuel cycle are derived as a result of the mass balance. Figures 2 and 3 show the material flows of the direct disposal and pyro-SFR fuel cycle [28].

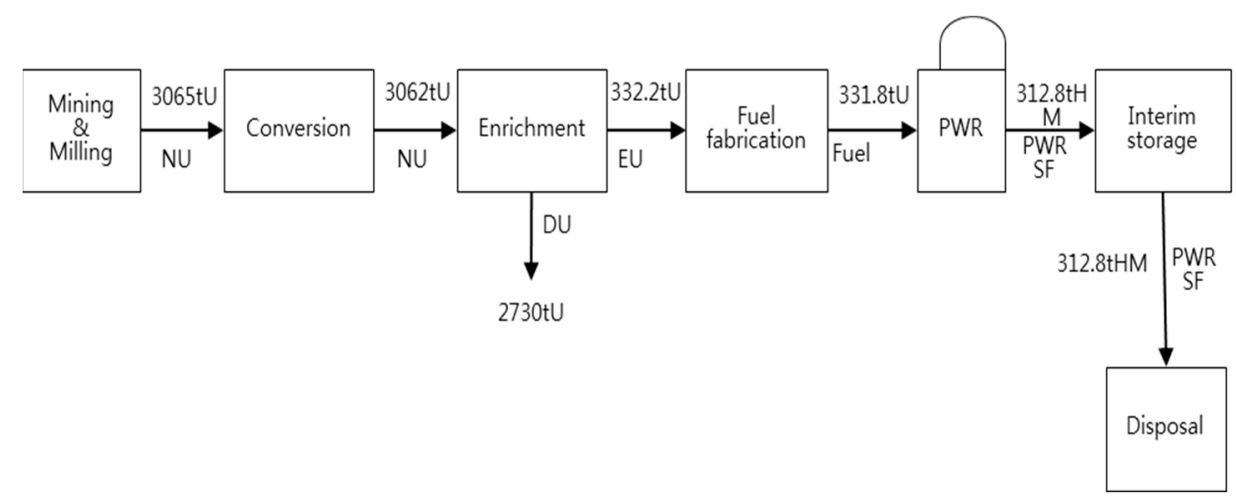

Figure 2. Material flow of direct disposal. Here, NU = natural uranium, DU = depleted uranium, $\mathrm{EU}=$ enriched uranium, PWR SF = pressurized-water reactor spent nuclear fuel. 


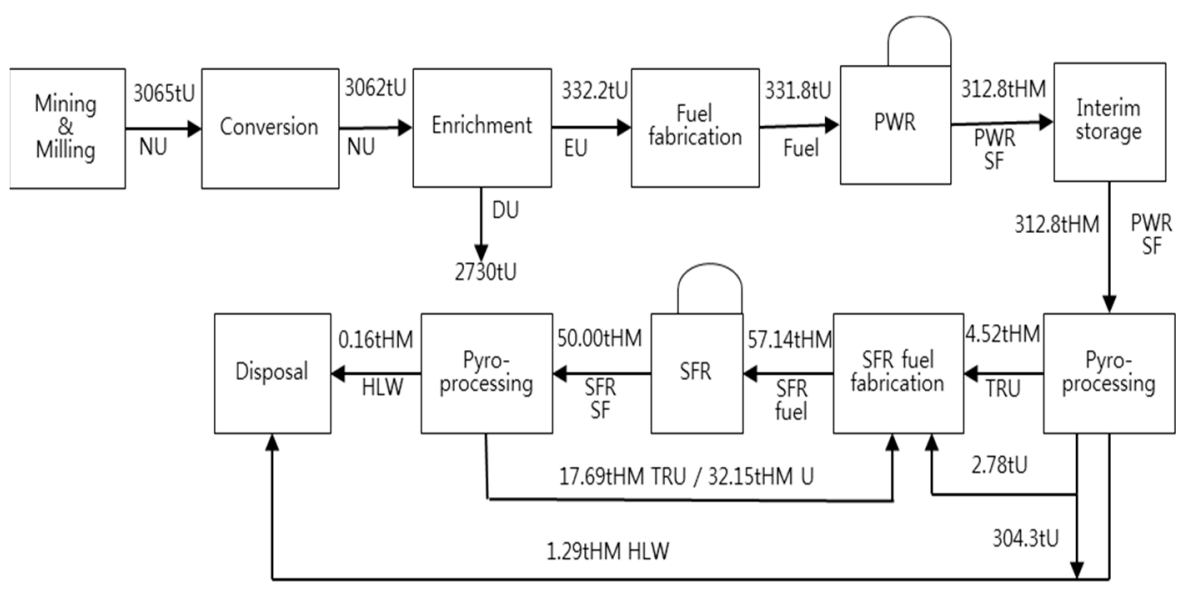

Figure 3. Material flow of pyro-SFR fuel cycle. Here, HLW = high-level radioactive waste, SFR $\mathrm{SF}=$ sodium-cooled fast reactor spent nuclear fuel, TRU = trans-uranium.

Tables 4 and 5 show the reactor-specific characteristics required for the nuclear fuel cycle analysis. Table 4 presents the parameter values that were assumed with reference to the performance of the PWR operated in Korea. Although the actual load factor varies considerably after the government's de-nuclearization policy, 0.85 is considered appropriate. The burn-up of spent fuel was also assumed to be $55 \mathrm{GWd} / \mathrm{tU}$, although there were variations. In addition, because an SFR has not been constructed in Korea to date, the parameter values were assumed as shown in Table 5 based on the conceptual design. Table 6 also shows the actinide inventory in spent fuel of a PWR and an SFR.

Table 4. PWR specifications.

\begin{tabular}{cc}
\hline Variables & Values \\
\hline Burnup (MWd/tHM) & 55,000 \\
\hline Load factor (\%) & 85 \\
\hline Thermal efficiency (\%) & 34 \\
\hline Capacity (MWe) & 1000 \\
\hline Initial enrichment (wt $\%)$ & 4.5 \\
\hline Natural uranium enrichment $(\mathrm{wt} \%)$ & 0.711 \\
\hline
\end{tabular}

Table 5. SFR specifications.

\begin{tabular}{cc}
\hline Variables & Values \\
\hline Burnup (MWd/tHM) & 133,000 \\
\hline Load factor $(\%)$ & 85 \\
\hline Thermal efficiency (\%) & 39 \\
\hline Capacity (MWe) & 400 \\
\hline TRU (trans-uranium) ratios of nuclear fuel & 0.389 \\
\hline
\end{tabular}

\subsection{Input Data}

The input data for the comparative evaluation of direct disposal and pyro-SFR fuel cycles are shown in Table 7. Power generation costs in Table 7 were calculated using a static material flow, which was based on the nuclear fuel cycle cost analysis model. 
Table 6. Actinide composition of spent fuel.

\begin{tabular}{ccc}
\hline & Actinide & Composition (wt $\%)$ \\
\hline \multirow{3}{*}{ PWR SF } & $\mathrm{U}$ & 92.92 \\
\cline { 2 - 3 } & $\mathrm{Pu}$ & 1.16 \\
\cline { 2 - 3 } & $\mathrm{MA}$ & 0.20 \\
\cline { 2 - 3 } & $\mathrm{FP}$ & 5.72 \\
\hline \multirow{3}{*}{ SFR SF } & $\mathrm{U}$ & 55.66 \\
\cline { 2 - 3 } & $\mathrm{Pu}$ & 26.15 \\
\cline { 2 - 3 } & $\mathrm{MA}$ & 4.38 \\
\hline
\end{tabular}

Table 7. Input data of multi-criteria decision-making model.

\begin{tabular}{|c|c|c|c|c|}
\hline \multirow{2}{*}{ Evaluation Criteria } & \multirow{2}{*}{ Evaluation Index } & \multicolumn{2}{|c|}{ Alternatives } & \multirow{2}{*}{ Remarks } \\
\hline & & Direct Disposal & Pyro-SFR Fuel Cycle & \\
\hline \multirow{2}{*}{ Safety } & $\begin{array}{l}\text { Radiation exposed dose } \\
\text { rate(mSv/year) }\end{array}$ & 10 & 0.05 & $\begin{array}{l}\text { Nuclear safety and security commission Notice } \\
\text { No. 2016-27 [24] }\end{array}$ \\
\hline & $\begin{array}{l}\text { Waste toxicity } \\
\left(\mathrm{m}^{3} \mathrm{H}_{2} \mathrm{O} / \mathrm{GWe}\right)\end{array}$ & $9.48 \times 10^{9}$ & $2.25 \times 10^{7}$ & KAERI/RR-3426/2011 [2] \\
\hline Resource utilization & $\begin{array}{l}\text { Natural uranium requirement } \\
\qquad(\mathrm{tU} / \mathrm{TWh})\end{array}$ & 20.58 & 13.86 & Advanced Fuel Cycle Cost Basis, INL (2017) [29] \\
\hline \multirow{4}{*}{$\begin{array}{l}\text { Environmental } \\
\text { elements }\end{array}$} & $\begin{array}{l}\text { High-level waste } \\
\text { (t/TWh) }\end{array}$ & 2.23 & 0.027 & Advanced Fuel Cycle Cost Basis, INL (2017) [29] \\
\hline & $\begin{array}{l}\text { LILW waste * } \\
\left(\mathrm{m}^{3} / \mathrm{TWh}\right)\end{array}$ & 18.89 & 21.22 & Advanced Fuel Cycle Cost Basis, INL (2017) [29] \\
\hline & $\begin{array}{l}\text { Cs/Sr waste } \\
(\mathrm{kg} / \mathrm{TWh})\end{array}$ & 0 & 12.36 & Advanced Fuel Cycle Cost Basis, INL (2017) [29] \\
\hline & $\begin{array}{l}\text { HLW repository area } \\
\left(\mathrm{m}^{2} / \mathrm{TWh}\right)\end{array}$ & 848.44 & 10.25 & KAERI/TR-7024/2017 [30] \\
\hline \multirow[t]{2}{*}{ Economics } & $\begin{array}{c}\text { Generation cost } \\
\text { (Levelized cost) } \\
(\text { mills } / \mathrm{kWh})\end{array}$ & 52.78 & 55.83 & Advanced Fuel Cycle Cost Basis, INL (2017) [29] \\
\hline & $\begin{array}{l}\text { Capital investment } \\
(\$ / \mathrm{kWe})\end{array}$ & 4000 & $4331 *(\mathrm{SFR}=5014)$ & Advanced Fuel Cycle Cost Basis, INL (2017) [29] \\
\hline \multirow{2}{*}{$\begin{array}{l}\text { Proliferation } \\
\text { resistance }\end{array}$} & $\begin{array}{c}\text { Nuclear material for } 1 S Q \\
\text { equivalents }(\mathrm{kg})\end{array}$ & 698.63 & 14.4 & KAERI/TR-3928/2009 [25] \\
\hline & $\begin{array}{l}\text { The value of utility function for } \\
\text { facility detection }\end{array}$ & 1 & 0.9 & KAERI/TR-3928/2009 [25] \\
\hline Public acceptance & $\begin{array}{l}\text { Supporting fund } \\
\text { (Unit: hundred million won } \\
\text { (KRW)/facility) }\end{array}$ & 19,988 & 2746 & KAERI internal data \\
\hline
\end{tabular}

* PWR capital investment cost $\times($ PWR capacity/Total capacity $)+$ SFR investment cost $\times$ (SFR capacity/Total capacity).

\section{Multi-Criteria Decision-Making Method}

\subsection{AHP (Analytic Hierarchy Process)}

The AHP is a powerful yet simple method for making decisions. It is commonly used for project prioritization and selection. Although researchers have invented and evaluated different methods of prioritizing projects in recent decades, it is known that AHP remains an efficient method.

Next, the mathematical model is described. If the criteria are $x_{i} \ldots x_{j}$ and the weight is $w_{i}$, A denotes the relative weight between the evaluation criteria $x_{i}$ and $x_{j}$, and it can be defined as $\mathrm{A}=a_{i j}=w_{i} / w_{j}$. Saaty argued that the eigenvector method has the advantage of not only producing better estimates than other weighting methods, but also measuring the 
consistency of pairwise-comparisons' judgments [10]. The weights are represented using the matrix (1) [10].

$$
\mathrm{A}=\left[\begin{array}{lll}
a_{11} & a_{12} & a_{13} \\
a_{21} & a_{22} & a_{23} \\
a_{31} & a_{32} & a_{33}
\end{array}\right]
$$

Here, the matrix A shows a pairwise comparison. These numerical values in the matrix A represent the pairwise comparisons of evaluation criteria such as safety, resource utilization, environment, economics, proliferation resistance, and public acceptance. Namely, the entry $\left(a_{i j}\right)$ in the $i^{t h}$ row and the $j^{t h}$ column of matrix $\mathrm{A}$ is the importance of criterion $i$ compared to that of criterion $\mathrm{j}$. For example, $a_{13}=3$ means that the first objective (safety) is three times as important as the third objective (environment). It follows that entries in the diagonal of matrix $\mathrm{A}$ are equal to 1 . Thus, if $a_{13}$ is 3 , then $a_{31}$ is $1 / 3$.

In the AHP method, the geometric mean is used to cover the evaluators' pairwise comparative evaluation data into a group opinion.

Equation (2) shows the squaring evaluators' pairwise comparative evaluation matrix.

$$
\mathrm{A}=\prod_{k=1}^{n} a_{i j}^{k}=\left[\begin{array}{lll}
a_{11} & a_{12} & a_{13} \\
a_{21} & a_{22} & a_{23} \\
a_{31} & a_{32} & a_{33}
\end{array}\right]\left[\begin{array}{lll}
a_{11} & a_{12} & a_{13} \\
a_{21} & a_{22} & a_{23} \\
a_{31} & a_{32} & a_{33}
\end{array}\right]
$$

where $a_{i j}^{k}=$ the comparative score of evaluator $\mathrm{k}$ between criterion $i$ and criterion $j$. The $\Pi$ denotes the multiplication.

Meanwhile, the weight eigenvector W can be expressed as Equation (3) [10].

$$
\begin{aligned}
& \mathrm{W}=\left[\begin{array}{c}
w_{1} \\
w_{2} \\
\vdots \\
w_{n}
\end{array}\right] \\
& \text { Here, } w_{j}=\frac{1}{n} \sum_{j=1}^{n} \frac{a_{i j}}{\sum_{k=1}^{n} a_{k j}}
\end{aligned}
$$

Finally, we can use Equation (4) to calculate the results of group opinion with the matrix A by multiplying by the weight vector $W$.

$$
S_{G}=A W
$$

where $S_{G}=$ the score results of group opinion, $A=$ the squaring evaluators' pairwise comparative evaluation matrix, $W=$ weight vector.

In addition, we used Equation (5) to calculate the eigenvalue $\lambda_{i}$, which is an input value of Equation (6).

$$
\lambda_{i}=\frac{w_{i}}{\sum_{i=1}^{n} w_{i}}
$$

In addition, the AHP method can analyze reliability using a consistency index $(\mathrm{CI})$, as shown in Equation (6) [10]. If the consistency ratio (CR, as in Equation (7)), is less than 0.1, it means that it is reliable.

$$
\begin{gathered}
\mathrm{CI}=\frac{\lambda_{\max }-n}{n-1}, \lambda_{\max } \geq n \\
\mathrm{CR}=\frac{\mathrm{CI}}{\mathrm{RI}}
\end{gathered}
$$

The Random Index $(R I)$ is shown in Table 8. 
Table 8. The number of evaluation criteria and RI.

\begin{tabular}{cc}
\hline \# of Evaluation Criteria & RI \\
\hline 1 & 0.000 \\
2 & 0.000 \\
3 & 0.580 \\
4 & 0.901 \\
5 & 0.121 \\
6 & 0.241 \\
7 & 0.321 \\
8 & 0.411 \\
9 & 0.451 \\
10 & 0.491 \\
11 & 0.510 \\
\hline
\end{tabular}

In addition, the AHP method calculates weights for various evaluation criteria by performing a pairwise-comparison according to the expert's judgment, and then calculates the weights of detailed evaluation indexes using these values. The eigenvalue is used as the weights of the criteria. In addition, the final weights can be used as weights for other decision-making methods.

\subsection{TOPSIS (Technique for Order Preference by Similarity to Ideal Solution)}

The TOPSIS method is a multi-criteria decision-making method and is widely used in industrial engineering. The optimal alternative is derived through the following procedure.

First, a decision matrix is derived from the normalized input value of evaluation criteria for each alternative. Evaluation indicators of nuclear fuel cycle alternatives have different units of measure. In addition, a large variation occurs in each evaluation indicator. Namely, if some evaluation criteria have a small deviation in the value of the evaluation indicators between nuclear fuel cycle alternatives, whereas some evaluation criteria have a large deviation in the value of the evaluation indicators between nuclear fuel cycle alternatives, the evaluation results will be greatly impacted by the criteria with large deviations in multi-criteria decision making. Therefore, in general, it is desirable to normalize the input values so that all the input values of evaluation indicators are between 0 and 1 . Finally, this normalization method shows better results than the de-normalization method of input data. There are several normalization methods, such as the minimum-maximum method, the maximum method, the sum method, and the vector method [31]. We used the minimum-maximum method, as shown Equation (8), because the greatest and the least input values in the considered evaluation indicators of nuclear fuel cycle are used.

To calculate the normalized decision matrix, the normalized values $r_{i j}$ were calculated using Equation (8) [32]. We assumed that the decision matrix with $\mathrm{m}$ alternatives and $\mathrm{n}$ criteria is represented as $\mathrm{T}=\left(r_{i j}\right)_{m \times n}$.

$$
\mathrm{T}=\left[\begin{array}{ccc}
r_{11} & \ldots & r_{1 n} \\
\ldots & \ldots & \ldots \\
r_{m 1} & \ldots & r_{m n}
\end{array}\right], r_{i j}=\frac{x_{i j}-\min _{j}\left(x_{i j}\right)}{\max _{j}\left(x_{i j}\right)-\min _{j}\left(x_{i j}\right)}
$$

Here, $r_{i j}=$ the normalized value of the $i$-th row and $j$-th column value of the decision matrix $\mathrm{T}$.

Second, the importance of evaluation criteria is adjusted by using weights. For this purpose, the assumptions about the weight $W_{j}$ of each evaluation criteria are given in Equation (9).

$$
W_{j}, j=1 \ldots n, \sum_{j=1}^{n} W_{j}=1
$$


Third, each value in the normalized decision matrix is multiplied by the associated weight, as shown in Equation (10).

$$
v_{i j}=w_{j} r_{i j} \text { for all } i, j
$$

Fourth, if a large value is the preferred evaluation criterion, the best solution $A_{b}$ and the worst solution $A_{w}$ are as shown in Equations (11) and (12).

$$
\begin{aligned}
& A_{b} ; V_{j}^{+}=\left\{V_{1}^{+}, V_{2}^{+}, \ldots, V_{n}^{+}\right\}=\left\{\max _{j}\left(V_{i j}\right)\right\} \\
& A_{w} ; V_{j}^{-}=\left\{V_{1}^{-}, V_{2}^{-}, \ldots, V_{n}^{-}\right\}=\left\{\min _{j}\left(V_{i j}\right)\right\}
\end{aligned}
$$

Fifth, the disparity of alternatives is calculated. That is, as in Equations (13) and (14), the distances of the best solution and the worst solution are calculated from the corresponding values.

$$
\begin{aligned}
& d_{i b}=\sqrt{\sum_{j=1}^{n}\left(V_{i j}-V_{j}^{+}\right)^{2}}, \mathrm{i}=1,2, \ldots, \mathrm{m} \\
& d_{i w}=\sqrt{\sum_{j=1}^{n}\left(V_{i j}-V_{j}^{-}\right)^{2}}, \mathrm{i}=1,2, \ldots, \mathrm{m}
\end{aligned}
$$

Here, $d_{i b}=$ the distance of the best solution and $d_{i w}=$ the distance of the worst solution.

Sixth, the relative proximity to the best and the worst solutions is evaluated, as shown in Equations (15) and (16).

$$
\begin{aligned}
C C_{i b} & =\frac{d_{i b}}{d_{i b}+d_{i w}} \\
C C_{i w} & =\frac{d_{i w}}{d_{i b}+d_{i w}}
\end{aligned}
$$

Here, $C C_{i b}=$ the relative proximity to the best solutions, $C C_{i w}=$ the relative proximity to the worst solutions.

Seventh, the preference rank of each alternative is determined. That is, the closer to the best value, and the farther away from the worst value, the results, the better the option. Based on these criteria, preferences for each alternative are determined.

\subsection{PROMETHEE (Preference Ranking Organization Method for Enrichment Evaluations)}

The most important feature of the PROMETHEE method is the use of a preference function. That is, the evaluator selects the preference function of each evaluation criterion that is judged to be the most suitable among various preference functions in order to determine the degree of preference for each alternative. However, the preference function has the disadvantage that the concept of subjective preference is involved. The evaluator generally selects the preference function from the six preference functions considering the nature of the evaluation criteria such as quantitative or qualitative data. Evaluators select one of the preferred functions for each of the evaluation criteria and perform a comparative evaluation on the evaluation criteria. In general, the quantitative evaluation criteria are selected from V-shape, linear, and Gaussian criteria, and the qualitative evaluation criteria are selected from U-shape and level criteria.

In addition, after selecting a preference function that meets the evaluation criteria among the six preference functions, the corresponding preference threshold is set. The preference index is calculated by applying the relative weight of the evaluation criteria. The calculated preference index is used to calculate the Leaving Flow $\left(\varphi^{+}\right)$, which is a value that favors or controls other alternatives, and the Entering Flow $\left(\varphi^{-}\right)$, which is a value that is preferred or governed by other alternatives. The six preference functions are shown in Table 9. 
Table 9. Preference function.

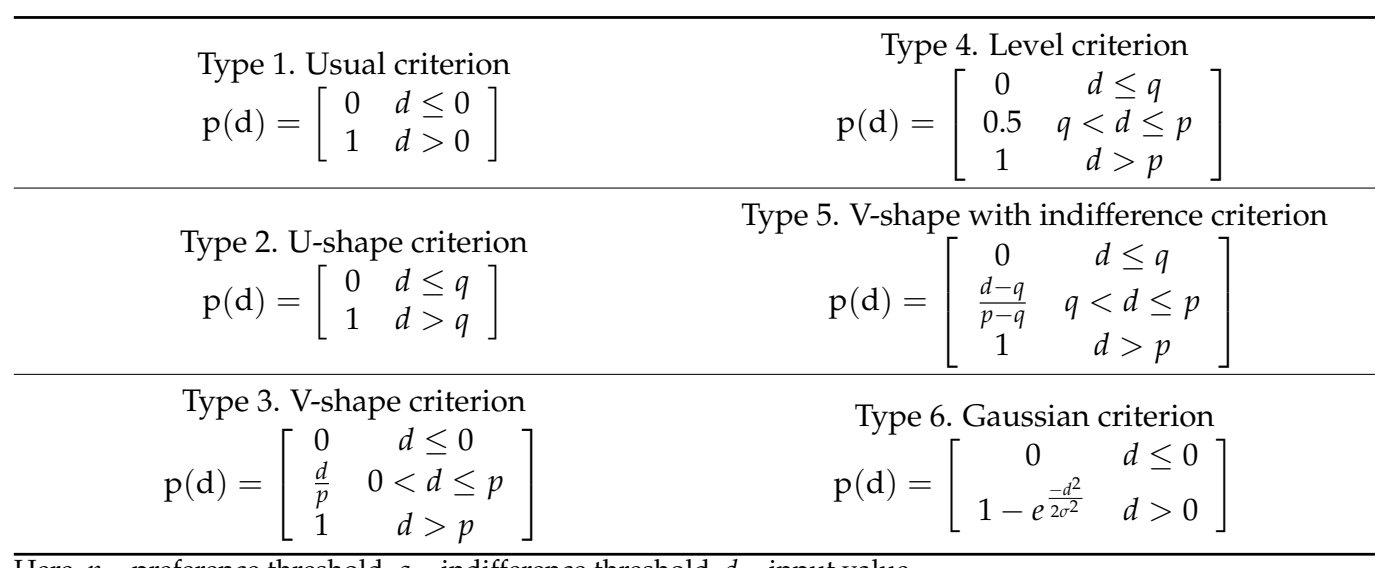
Here, $p=$ preference threshold, $q=$ indifference threshold, $d=$ input value.

Most preference function shapes include one or two threshold values. The preference threshold is the maximum difference of the input values. In addition, the calculation method is delineated in Equation (22). Figure 4 shows the $x$-coordinate of a preference threshold (PT) and an indifference threshold of a typical linear preference function.

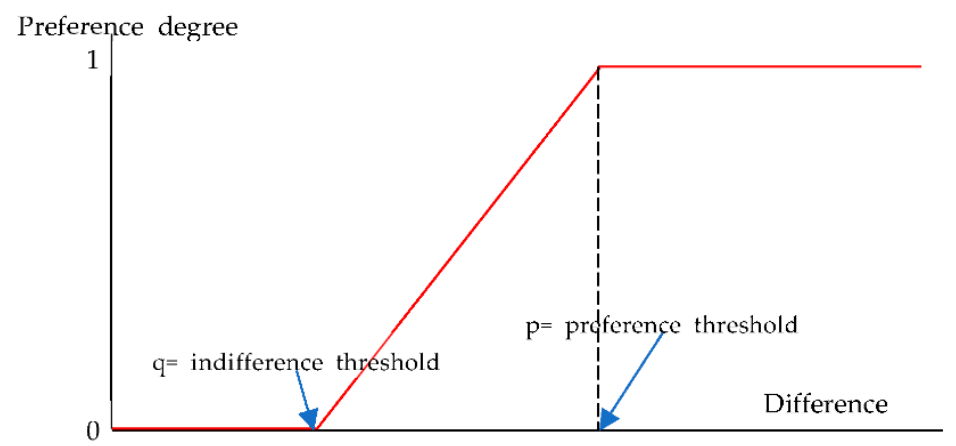

Figure 4. The preference threshold and indifference threshold.

The calculation procedure of the PROMETHEE method is as follows. First, as shown in Equation (17) [27], the difference is calculated through a pairwise comparison for any evaluation criteria.

$$
d_{j}(a, b)=p_{j}(a)-p_{j}(b), 0<d_{j}(a, b)<1
$$

where $d_{j}(a, b)$ denotes the difference between the evaluations of $a$ and $b$ for each criterion.

Second, $a$ preference function is applied. That is, $a$ specific preference function such as Equation (18) is selected from the six general preference functions. Then, the relevant parameters are determined.

$$
P_{j}(a, b)=F_{j}\left[d_{j}(a, b)\right]
$$

Third, a preference degree is calculated using Equation (19) [27].

$$
\pi(a, b)=\sum_{j=1}^{k} P_{j}(a, b) W_{j}
$$

Here, $\pi(a, b)=$ a preference degree; $\mathrm{a}$ is preferred to $\mathrm{b}$, whereas $\pi(b, a): \mathrm{b}$ is preferred to a. Assume we have a set of weights for each criterion for $w_{j}, j=1, \ldots n$.

Fourth, using Equations (20)-(22), the input flow $\varphi^{+}(a)$, the leakage flow $\varphi^{-}(a)$, and the net flow $\varphi(a)$ are calculated. Finally, the larger the net flow, the better the alterna- 
tive. This is because the larger the net flow, the higher the preference compared to the other alternatives.

$$
\begin{aligned}
\varphi^{+}(a) & =\frac{1}{n-1} \sum_{b \in A} \pi(a, b) \\
\varphi^{-}(a) & =\frac{1}{n-1} \sum_{b \in A} \pi(b, a) \\
\varphi(a) & =\varphi^{+}(a)-\varphi^{-}(a)
\end{aligned}
$$

\subsection{Comparison of MCDM Methodology}

There are advantages and disadvantages of each decision-making method, as shown

\begin{tabular}{|c|c|}
\hline MCDM & Advantages \\
\hline \multirow{3}{*}{ AHP } & $\begin{array}{l}\text { Decision making is performed by using a hierarchical process, and thus conflicting concepts can be applied. } \\
\text { Quantitative results can be obtained by using the systematical ratio scale of relative importance for alternatives. } \\
\text { All information (quantitative, qualitative, and intuitive data) can be considered. } \\
\text { Compared to the case of using mathematical functions, the calculation procedure is simple. } \\
\text { Group decision making is possible. }\end{array}$ \\
\hline & Disadvantages \\
\hline & $\begin{array}{l}\text { A theoretical framework for the hierarchy process of decision making is needed. } \\
\text { If the independence of constituent hierarchy elements between alternatives is not secured or the setting of the } \\
\text { hierarchical level is incorrect, the decision-making results will not be reliable. } \\
\text { Layer depth (number of evaluation level) and width (number of criteria elements) is limited. } \\
\text { Difficult to apply for more than seven evaluation criteria. } \\
\text { There are hidden assumptions such as consistency and the difficulty of repeating some evaluation process. } \\
\text { Difficulties of conflict removal between decision makers' opinion. }\end{array}$ \\
\hline
\end{tabular}
in Table 10.

Table 10. The advantages and disadvantage of MCDM [33-35].

$$
\text { Advantages }
$$

Easy to understand the decision-making process.

The results indicate intuitive meaning because of the relative proximity to the ideal solution.

Human rational choice that considers the best and worst solution at the same time is possible.

Provision of a well-structured analytical framework for ranking alternatives.

$$
\text { Disadvantages }
$$

The decision matrix cannot be calculated by hand because there are many rows and columns in the matrix, and software for calculation such as Excel is required.

Normalization of input data is required.

Multi-collinearity effects should be solved.

There is a high possibility that the decision making will be decided by the best and worst values of input data.

\section{Advantages}

By using the evaluator's subjective information such as the preferred functions and preference threshold on the basis of preference ranking, decision making with complex comparison between alternatives is possible.

There is a flexibility of application compared to AHP and TOPSIS because of the use of various preference functions.

PROMETHEE If evaluators determine the preference function and the input value of the preference threshold, new alternatives can be easily added or can be effectively removed.

If the evaluator knows the calculation algorithm, it is relatively easy to calculate the MCDM results of back-end nuclear fuel cycle alternatives, and less cost and time are incurred.

\section{Disadvantages}

Exists for subjectivity in selection of preference function.

When a new alternative is added, there is a problem in which the ranking may be reversed. 


\section{Results and Discussion}

By applying the results of weighting factors for the nuclear fuel cycle evaluation criteria, multi-criteria decision-making results of the direct disposal and pyro-SFR fuel cycle alternatives were obtained. Rank-reciprocal weights were derived from previous studies from the 2012 survey [8].

\subsection{AHP Evaluation Results}

Figure 5 shows the results from calculating the priorities for the two alternatives, direct disposal and pyro-SFR fuel cycle, using the AHP method and the rank weights in Table 3. The calculations show that the alternative of pyro-SFR is more advantageous than direct disposal.

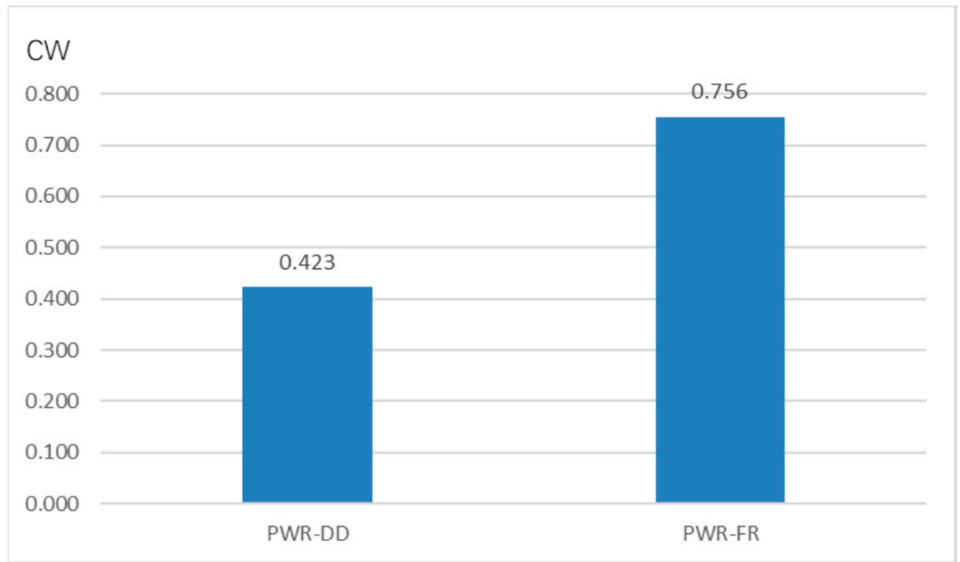

Figure 5. MCDM results using AHP and rank weights.

\subsection{TOPSIS Evaluation Results}

Figure 6 shows the results of multi-criteria decision-making using the TOPSIS method and the rank weights in Table 3. As shown in Figure 6, the Pyro-SFR fuel cycle alternative is closer to the best value and farther away from the worst value than the direct disposal alternative. The closer to the positive ideal solution, and the farther away from the negative ideal solution, the better the solution point.

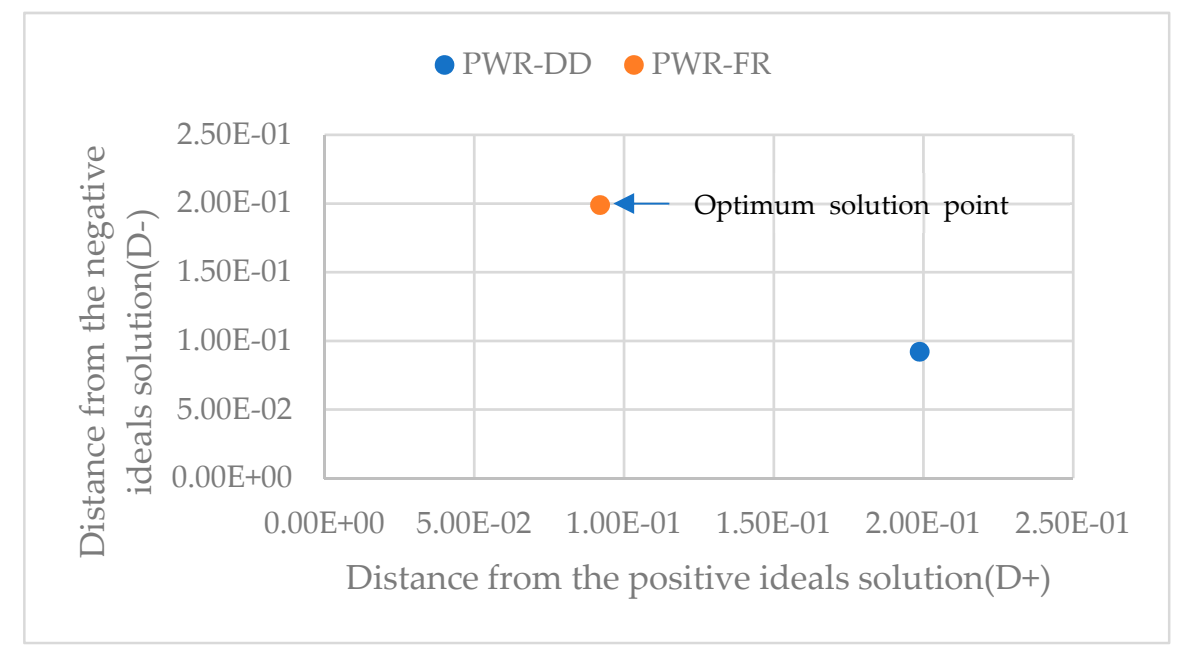

Figure 6. TOPSIS evaluation results.

Therefore, the pyro-SFR fuel cycle alternative was shown to be more advantageous than direct disposal. 


\subsection{PROMETHEE Evaluation Results}

We must first determine preference functions and preference thresholds in order to assess and evaluate nuclear fuel cycle alternatives.

In this study, we used the preference function, as shown in Table 11, and the values of the preference threshold were calculated using Equation (22).

$$
\mathrm{PT}=\frac{\text { Max }- \text { Min }}{N A}
$$

Table 11. Preference function and preference threshold.

\begin{tabular}{|c|c|c|c|}
\hline Evaluation Index & Preference Function & Preference Threshold & Unit \\
\hline Radiation exposed dose rates & V-shape & 4.975 & $\mathrm{mSv} /$ year \\
\hline Waste toxicity level & V-shape & $4,728,750,000$ & $\mathrm{~m}^{3} \mathrm{H}_{2} \mathrm{O} / \mathrm{GWe}$ \\
\hline NU required per energy generated & V-shape & 3.36 & $\mathrm{tU} / \mathrm{TWh}$ \\
\hline HLW & V-shape & 1.1015 & Ton/TWh \\
\hline LILW Volume & V-shape & 1.165 & $\mathrm{~m}^{3} / \mathrm{TWh}$ \\
\hline Cs/Sr waste & V-shape & 6.18 & $\mathrm{Kg} / \mathrm{TWh}$ \\
\hline $\begin{array}{l}\text { Land Use for HLW disposal per } \\
\text { energy generated }\end{array}$ & V-shape & 419.095 & $\mathrm{~m}^{2} / \mathrm{TWh}$ \\
\hline Levelized cost of Electricity Generation & V-shape & 1.525 & mills/kWh \\
\hline Capital investment cost & V-shape & 165.5 & $\$ / \mathrm{kWe}$ \\
\hline Nuclear material for $1 \mathrm{SQ}$ equivalent & V-shape & 342.115 & $\mathrm{Kg}$ \\
\hline The value of utility function for facility detection & V-shape & 0.05 & $\mathrm{~N} / \mathrm{A}$ \\
\hline Public acceptance (supporting fund) & Usual & 8621 & $\begin{array}{l}\text { Hundred million won } \\
(\mathrm{KRW}) / \text { facility }\end{array}$ \\
\hline
\end{tabular}

Here, $\mathrm{PT}=$ preference threshold, $\mathrm{Max}=$ maximum value, $\mathrm{Min}=$ minimum value, $\mathrm{NA}=$ number of alternatives $=2$.

Figure 7 shows the normalized values of the detailed indicators used in PROMETHEE. Except for the nuclear proliferation resistance, generation costs, low and medium level waste, and the Cs-Sr waste, the pyro-SFR fuel cycle evaluation indicators were found to be more favorable than direct disposal.

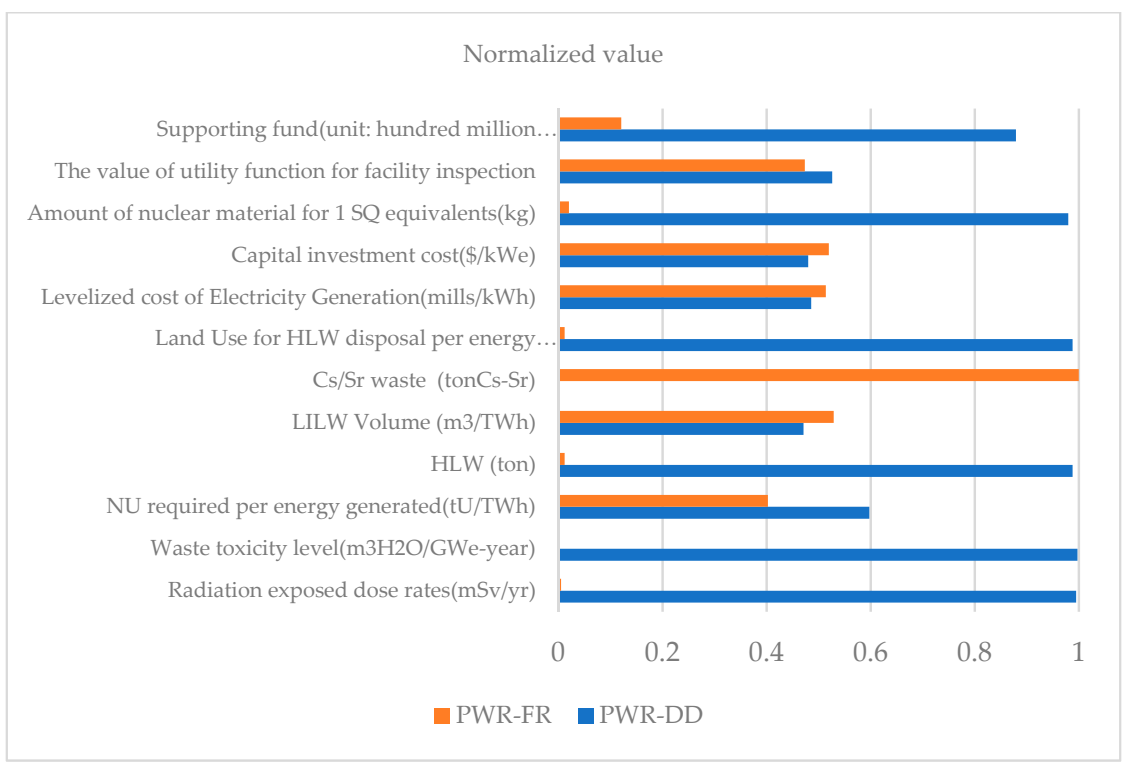

Figure 7. Evaluation index for PROMETHEE method. 
Figure 8 shows the results from evaluating the nuclear fuel cycle with direct disposal and pyro-SFR using the PROMETHEE method and the rank weights from Table 3. According to the results of the evaluation, direct disposal is more favorable than the pyro-SFR fuel cycle. This is different from the calculation results of AHP and TOPSIS.

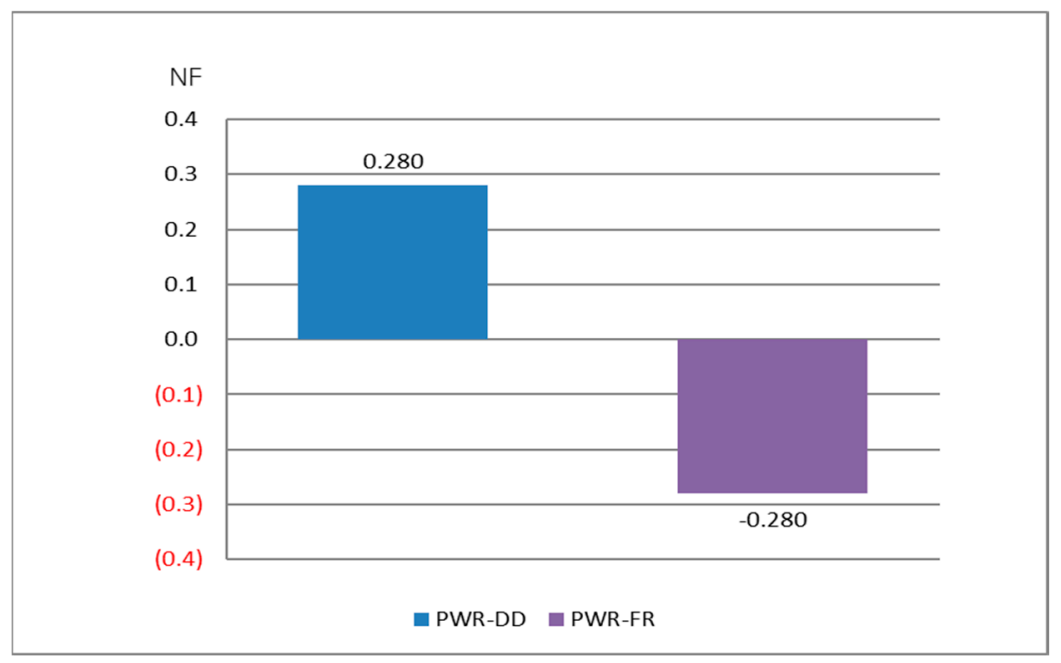

Figure 8. MCDM results using PROMETHEE and rank weights.

Table 12 shows the differences of evaluation results using MCDM methods. In Table 12, the relative closeness can be determined by both CCib of Equation (14) and CCiw of Equation (15).

Table 12. MCDM evaluation results.

\begin{tabular}{cccc}
\hline AHP & Alternatives & Final Score & Rank \\
\hline & PWR-DD (Direct Disposal) & 0.423 & 2 \\
\hline TOPSIS & PWR-FR (Fast Reactor) & 0.756 & 1 \\
\hline & Alternatives & Relative closeness (coefficient) & Rank \\
\hline PROMETHEE & PWR-DD & 0.260 & 2 \\
\hline & PWR-FR & 0.740 & 1 \\
\hline & Alternatives & Net flow (Ø) & Rank \\
\hline & PWR-DD & 0.280 & 1 \\
\hline
\end{tabular}

\subsection{Sensitivity Analysis}

Multi-criteria decision-making methods rely heavily on the weights of evaluation criteria. A weight sensitivity analysis of the method of assigning weights according to the evaluator's attributes is required [30]. For example, environmentalists will give greater weight to environmental criteria, and economists will consider economics as important criteria (Table 13). Therefore, in this study, the weight of the important criteria was assigned to $1 / 2$ and the other evaluation criteria were evenly distributed according to the evaluation attributes of the evaluator. The goal of the sensitivity analysis was to identify whether weighting could change the rank of nuclear fuel cycle alternatives and to produce information that can be used to establish nuclear fuel cycle policy. The groups of evaluators were first classified into neutral groups, general public groups, resource protection groups, environmentalist groups, economist groups, anti-nuclear groups, and community groups. Here, the neutral group refers to a group that evenly distributes the weights of all the evaluation criteria. The public group was regarded as a group of ordinary people who put 
the safety of the nuclear facility first. This is because, following the Fukushima nuclear power plant accident in Japan, many people appear to have increased interest in the safety of nuclear power plants. Finally, the local people group refers to local people living close to nuclear power plants.

Table 13. Weights based on evaluator attributes.

\begin{tabular}{cccccccc}
\hline \multirow{2}{*}{ Criteria } & \multicolumn{5}{c}{ Evaluator Attributes } \\
\cline { 2 - 8 } & Neutral & Public & $\begin{array}{c}\text { Resource } \\
\text { Conservationism }\end{array}$ & Environmentalism & Economist & Anti-Nuclear & Local Resident \\
\hline Safety & $1 / 6$ & $1 / 2$ & $1 / 10$ & $1 / 10$ & $1 / 10$ & $1 / 10$ & $1 / 10$ \\
\hline Resource utilization & $1 / 6$ & $1 / 10$ & $\frac{1}{2}$ & $1 / 10$ & $1 / 10$ & $1 / 10$ & $1 / 10$ \\
\hline Environmental impact & $1 / 6$ & $1 / 10$ & $1 / 10$ & $1 / 2$ & $1 / 10$ & $1 / 10$ & $1 / 10$ \\
\hline Economic & $1 / 6$ & $1 / 10$ & $1 / 10$ & $1 / 10$ & $1 / 2$ & $1 / 10$ & $1 / 10$ \\
\hline Proliferation resistance & $1 / 6$ & $1 / 10$ & $1 / 10$ & $1 / 10$ & $1 / 10$ & $1 / 2$ & $1 / 10$ \\
\hline Public acceptance & $1 / 6$ & $1 / 10$ & $1 / 10$ & $1 / 10$ & $1 / 10$ & $1 / 10$ & $1 / 2$ \\
\hline
\end{tabular}

We used the PROMETHEE method because it is relatively easy to calculate the MCDM results of back-end nuclear fuel cycle alternatives, and requires less cost and time. From the results of the sensitivity analysis of weight according to the evaluator's characteristics using the PROMETHEE method, if the weight of public acceptance criteria is increased from $1 / 6$ to $1 / 2$ and other evaluation criteria are equally given $1 / 10$ weight, the rank of nuclear fuel cycle alternatives is reversed (Figure 9). That is, if the weight of the criteria for public acceptance is set to $1 / 6$, which is equally weighted, the direct disposal option is advantageous compared to the Pyro-SFR fuel cycle, whereas if the weight of the criterion for public acceptance changes from $1 / 6$ to $1 / 2$, the pyro-SFR fuel cycle alternative appears to be more advantageous than direct disposal. This is because the difference in subsidies used as a proxy variable of public acceptance is large between the two alternatives, and hence if the weight is increased, the preference of nuclear fuel cycle alternatives will be reversed because the net preference flow will be greatly affected by the proxy variable.

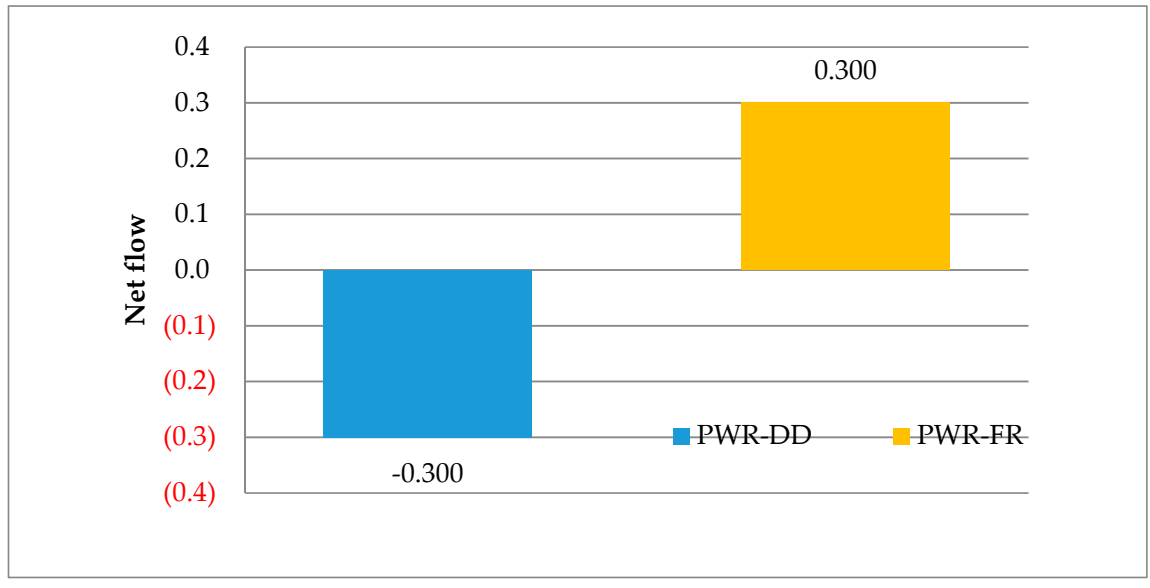

Figure 9. Net preference flow using $1 / 2$ weight of public acceptance criterion.

\section{Conclusions}

The evaluation results of the multi-criteria decision making for the pyro-SFR fuel cycle and direct disposal show different results for the TOPSIS and PROMETHEE methods. Specifically, in the PROMETHEE method, the direct disposal is more advantageous than the pyro-SFR fuel cycle alternative.

TOPSIS sets the most ideal value and the most negative value among the input values to each criterion as a parameter. We assumed parameters considering the concept of 
distance between the best alternative and the worst alternative, and the closeness between these two values was calculated. Preferability was determined by comparing the closeness coefficients. Therefore, the closer the input values of the detailed evaluation indicators to the ideal value, and the farther they are from the negative value, the better the option among the fuel cycle alternatives. In addition, the input value of the relevant evaluation criteria plays an important role when there is a large difference between the two alternatives in the proximity comparison of the high weight parameter values.

The advantages of TOPSIS are as follows: First, the calculation process is simpler and easier to understand than other multi-criteria decision-making methods. Second, it is easy to apply even if the number of evaluation criteria and detailed evaluation indexes is relatively large. For each alternative, the use of the "relative proximity" concept of ideal and negative alternatives can give a fairly intuitive meaning to the evaluation results. Third, the best and the worst alternatives can be considered at the same time, making it easier to choose a more reasonable alternative from the nuclear fuel cycle alternatives.

The PROMETHEE method first selects the preference function including the preference threshold, and calculates the preferred outflow and the preferred inflow for the detailed evaluation indicators. Next, it prioritizes alternatives by calculating the net preference flow. Based on the concept of preference, decision makers' subjective judgment information (preferred function and preference threshold) can be applied to compare alternatives. When the decision maker decides the preference function and the preference threshold, the comparative evaluation is performed by the net preference flow calculation algorithm. Even if a new alternative is added or deleted, the comparison between the alternatives can be performed more efficiently than other multi-criteria decision-making methods. However, it also has the disadvantage of reducing objectivity due to the use of subjective judgment in the selection of the preference function and preference threshold.

From the evaluation results, it is difficult to judge which method is better because there are advantages and disadvantages of each decision-making method. In the future, we plan to investigate nuclear fuel cycle analysis cases using an advanced MCDM method, and will research these advanced MCDM methods. In addition, it is expected that a nuclear fuel cycle analysis will be possible with more accurate parameter values when the SFR is constructed.

Author Contributions: The main theme of this paper was developed by S.K. and was coordinated by J.-S.K., S.K. wrote the manuscript and processes the submission of this paper. J.-S.K. prepared most of the equations, tables, and figures. D.-K.C. commented on the results and conclusions. All authors have read and agreed to the published version of the manuscript.

Funding: This work was supported by the Institute for Korea Spent Nuclear Fuel (iKSNF) and National Research Foundation of Korea(NRF) grant funded by the Korea government (Ministry of Science and ICT, MSIT) (2021M2E1A1085193).

Institutional Review Board Statement: Not applicable.

Informed Consent Statement: Not applicable.

Data Availability Statement: Not applicable.

Acknowledgments: This work was supported by the National Research Foundation of Korea (NRF) grant funded by the Korea government (MSIT: Ministry of Science and ICT), and the authors express their sincere gratitude for supporting this important work.

Conflicts of Interest: The authors declare no conflict of interest.

\section{Terminology}

Terminologies are as follows [36,37]. 


\begin{tabular}{|c|c|}
\hline MCDM & $\begin{array}{l}\text { Multiple-criteria decision-making (MCDM) or multiple-criteria } \\
\text { decision analysis (MCDA) is a sub-discipline of operations } \\
\text { research that explicitly evaluates multiple conflicting criteria in } \\
\text { decision making. Conflicting criteria are typical in evaluating } \\
\text { options: cost or price is usually one of the main criteria, and some } \\
\text { measure of quality is typically another criterion. Thus, MCDM } \\
\text { means the process of determining the best feasible solution } \\
\text { according to established criteria. }\end{array}$ \\
\hline AHP & $\begin{array}{l}\text { The analytic hierarchy process (AHP), also analytical hierarchy } \\
\text { process, is a structured technique for organizing and analyzing } \\
\text { complex decisions, based on mathematics and psychology. It was } \\
\text { developed by Thomas L. Saaty in the 1970s; Saaty partnered with } \\
\text { Ernest Forman to develop Expert Choice software in 1983, and } \\
\text { AHP has been extensively studied and refined since then. It } \\
\text { represents an accurate approach to quantifying the weights of } \\
\text { decision criteria. Individual experts' experiences are utilized to } \\
\text { estimate the relative magnitudes of factors through pair-wise } \\
\text { comparisons. Each of the respondents compares the relative } \\
\text { importance each pair of items using a specially } \\
\text { designed questionnaire. }\end{array}$ \\
\hline TOPSIS & $\begin{array}{l}\text { The Technique for Order of Preference by Similarity to Ideal } \\
\text { Solution(TOPSIS) is a multi-criteria decision analysis method, } \\
\text { which was originally developed by Ching-Lai Hwang and Yoon } \\
\text { in } 1981 \text { with further developments by Yoon in 1987, and Hwang, } \\
\text { Lai and Liu in 1993. TOPSIS is based on the concept that the } \\
\text { chosen alternative should have the shortest geometric distance } \\
\text { from the positive ideal solution (PIS) and the longest geometric } \\
\text { distance from the negative ideal solution (NIS). }\end{array}$ \\
\hline PROMETHEE & $\begin{array}{l}\text { PROMETHEE is a well-established decision support system } \\
\text { which deals with the appraisal and selection of a set of options } \\
\text { on the basis of several criteria, with the objective of identifying } \\
\text { the pros and the cons of the alternatives and obtaining a ranking } \\
\text { among them.The method called Preference Ranking Organisation } \\
\text { Method for Enrichment Evaluations (PROMETHEE) was } \\
\text { developed by Brans (1982), further extended by Brans and Vincke } \\
\text { (1985) and Brans and Mareschal (1994). It is an } \\
\text { outranking method. }\end{array}$ \\
\hline $\begin{array}{l}\text { Direct Disposal Spent } \\
\text { nuclear fuel (SNF) }\end{array}$ & $\begin{array}{l}\text { SNF constitutes the largest portion of high-level nuclear waste. } \\
\text { The radioactivity content of SNF decays so that it reaches } \\
\text { comparable levels of the natural uranium mined to manufacture } \\
\text { fresh fuel only after some } 100,000 \text { years. There is a need to } \\
\text { provide isolation of these radioactive materials from the } \\
\text { biosphere during this period. This is presently done by } \\
\text { implementing a strategy that consists of a storage period to cool } \\
\text { down the fuel elements after fission in the reactor followed by } \\
\text { their deep geological disposal. DD (Direct Disposal) means the } \\
\text { deep geological disposal method. }\end{array}$ \\
\hline $\begin{array}{l}\text { Pyro-SFR NFC Pyro-SFR } \\
\text { nuclear fuel cycle (NFC) }\end{array}$ & $\begin{array}{l}\text { This is highlighted as a competitive alternative to direct } \\
\text { disposal in terms of economic efficiency, because an efficient } \\
\text { reprocessing method is being re-examined in many states of the } \\
\text { world, such as United States and Korea. }\end{array}$ \\
\hline
\end{tabular}


Pyroprocessing (Pyro) Argonne National Laboratory pioneered the development of Argonne National Laboratory pyrochemical processing, or pyroprocessing, a high-temperature method of recycling reactor waste into fuel, demonstrating it paired with the EBR-II and then proposed commercializing it in the Integral Fast Reactor. In 2016, several pyroprocessing technologies for both light water and fast reactors, with most based on electrorefining to improve the technologies' commercial viability by increasing their process efficiency and scalability, were developed. South Korea is developing the pyroprocessing technology at Korea Atomic Energy Research Institute (KAERI).

Nuclear Fuel Cycle
The nuclear fuel cycle is the progression of nuclear fuel through a series of differing stages. It consists of steps in the front end, which are the preparation of the fuel, steps in the service period in which the fuel is used during reactor operation, and steps in the back end, which are necessary to safely manage, contain, and either reprocess or dispose of spent nuclear fuel. If spent fuel is not reprocessed, the fuel cycle is referred to as an open fuel cycle (or a once-through fuel cycle); if the spent fuel is reprocessed, it is referred to as a closed fuel cycle.

\section{References}

1. Ko, W.-I.; Jang, H.-R. Nuclear Fuel Cycle System Integrated Evaluation; KAERI/TR-4508; KAERI: Daejeon, Korea, $2011 ;$ pp. 12-36.

2. Ko, W.-I.; Jang, H.-R.; Kim, S.K. Development of System Engineering Technology for Nuclear Fuel Cycle; KAERI/RR-3426; KAERI: Daejeon, Korea, 2011; pp. 32-60.

3. Silvennoinen, P. Nuclear Fuel Cycle Optimization; Pergamon Press: Oxford, UK, 1982; pp. 40-45.

4. Parnell, G.S.; Driscoll, P.J.; Henderson, D.L. Decision Making in Systems Engineering and Management; John Wiley \& Sons, Inc.: Hoboken, NJ, USA, 2007; pp. 303-305.

5. Chang, T.Y.; Ku, C.C. Fuzzy filtering ranking method for multi-criteria decision making. Comput. Ind. Eng. 2021, $156,107217$. [CrossRef]

6. Dabous, S.A.; Ibrahim, F.; Feroz, S.; Alsyouf, I. Integration of failure mode, effects, and criticality analysis with multi-criteria decision-making in engineering applications: Part II-Non-manufacturing industries. Eng. Fail. Anal. 2021, 122, 105296. [CrossRef]

7. Hashemi, A.; Dowlatshahi, M.B.; Nezamabadi-Pour, H. Hossein Nezamabadi-pour. MFS-MCDM: Multi-label feature selection using multi-criteria decision making. Knowl. Based Syst. 2020, 206, 106365. [CrossRef]

8. Kim, S.K.; Kang, G.B.; Ko, W.I.; Youn, S.R.; Gao, R.X. A statistical approach for deriving key NFC evaluation criteria. Nucl. Eng. Technol. 2014, 46, 81-92. [CrossRef]

9. Jong, N.K.; Stone, P.; Keeney, R.L.; Raiffa, H. Decisions with Multiple Objectives_Preferences and Value Tradeoffs; Cambridge University Press: Cambridge, UK, 2003; pp. 66-82.

10. Wang, L.; Xu, S.B. An Illustrated Guide to the Analytic Hierarchy Process; BOKU: Vienna, Austria, 2015; pp. 35-38.

11. Saldanha, W.H.; Arrieta, F.R.; Ekel, P.I.; Machado-Coelho, T.M.; Soares, G.L. Multi-criteria decision-making under uncertainty conditions of a shell-and-tube heat exchanger. Int. J. Heat Mass Transf. 2020, 155, 119716. [CrossRef]

12. Soltaniyan, S.; Salehizadeh, M.R.; Taşcıkaraoğlu, A.; Erdinç, O.; Catalão, J.P. An interactive multi-criteria decision-making framework between a renewable power plant planner and the independent system operator, Sustainable Energy. Grids Netw. 2021, 26, 100447.

13. Dabous, S.A.; Ibrahim, F.; Feroz, S.; Alsyouf, I. Integration of failure mode, effects, and criticality analysis with multi-criteria decision-making in engineering applications: Part I-Manufacturing industry. Eng. Fail. Anal. 2021, 122, 105264. [CrossRef]

14. Gebre, S.L.; Cattrysse, D.; Alemayehu, E.; Van Orshoven, J. Multi-criteria decision making methods to address rural land allocation problems: A systematic review. Int. Soil Water Conserv. Res. 2021. [CrossRef]

15. Sung, K.K.; Won, I.K.; Hyo, J.L.; Sung, Y.C. The Derivation Method of Nuclear Fuel Cycle Evaluation Criteria Using a Factor Analysis; KAERI/TR-5264/2013; KAERI: Daejeon, Korea, 2013; pp. 13-14.

16. OECD/NEA. Advanced Nuclear Fuel Cycles and Radioactive Waste Management; NEA: Paris, France, 2006; pp. 21-28.

17. Lokhov, A.; Urso, M.E.; Cameron, R. OECD/NEA study on the economics of the back-end of nuclear fuel cycle. In Proceedings of the ICAPP, Jeju Island, Korea, 14-18 April 2013.

18. IAEA. Factors Affecting Public and Political Acceptance for the Implementation of Geological Disposal; IAEA-TECDOC-1566; IAEA: Vienna, Austria, 2007; pp. 10-16.

19. Kim, S.Y.; Wang, J. Changes in Attitudes toward Nuclear Public Acceptance of the World after the Fukushima Nuclear Accident. Korean Assoc. Policy Stud. 2014, 23, 57-89. 
20. Lee, G.; Song, H.-J.; Kim, J.-K.; Hwang, W.-D. Analysis of Factors Affecting Korean People's Public Acceptance of Nuclear Power. In Proceedings of the Korean Association for Policy Studies Spring Conference Proceeding, Seoul, Korea, 24-25 March 2011; pp. 535-555.

21. Park, C.H.; Kim, S.Y. Knowledge Effects and Functions in Determining Nuclear Public Acceptance: Focusing on Objective Knowledge and Subjective Knowledge. Adm. Artic. 2015, 53, 117-150.

22. Nguyen, V.P.; Yim, M.S. Examination of different socio economic factors that contribute to the public acceptance of nuclear energy. Nucl. Eng. Technol. 2018, 50, 767-772. [CrossRef]

23. Richard, M. Determination of relative importance of nonproliferation factors. In Proceedings of the Institute of Nuclear Materials Management 50th Annual Meeting, Tucson, AZ, USA, 12-16 July 2009.

24. Korea Nuclear Safety and Security Commission. [Notice No. 2016-27]: Repository; General Standards for High-Level Waste Repository [Enforcement Ordinance 2016.12.23]; NSSC: Seoul, Korea, 2016.

25. Jang, H.-R.; Ko, W.-I. Analysis of Proliferation Resistance of Nuclear Fuel Cycle Systems; KAERI/TR-3928/2009, Table 8; KAERI: Daejeon, Korea, 2009; p. 31.

26. Jang, H.-R.; Ko, W.-I. Analysis of Proliferation Resistance of Nuclear Fuel Cycle Systems; KAERI/TR-3928/2009, Table 19; KAERI: Daejeon, Korea, 2009; p. 47.

27. Kim, Y.R. Introduction to Decision Analysis-Second Edition; Myung kyung sa Press: Seoul, Korea, 2012; pp. 317-318.

28. Ko, W.-I.; Jang, H.-R. Development of Pyroprocess System Technologies; KAERI/RR-4173/2016, Table 3.2.3.11; KAERI: Daejeon, Korea, 2016; p. 198.

29. INL. Advanced Fuel Cycle Cost Basis-2017 Edition; INL/EXT-17-43826; INL.: Idaho Falls, ID, USA, 2017 ; pp. 11-49.

30. Hong, J.; Hyo, O.N.; Gao, R.; Chul, M.K.; Won, I.K. Application of Various Integrated Evaluation Methods for Nuclear Fuel Cycle System; KAERI/TR-7024/2017; KAERI: Daejeon, Korea, 2017; p. 40.

31. Sałabun, W.; Watróbski, J.; Shekhovtsov, A. Are MCDA Methods Benchmarkable? A Comparative Study of TOPSIS, VIKOR, COPRAS, and PROMETHEE II Methods. Symmetry 2020, 12, 1549. [CrossRef]

32. Shekhovtsov, A.; Sałabun, W. A comparative case study of the VIKOR and TOPSIS rankings similarity. Procedia Comput. Sci. 2020, 176, 3730-3740. [CrossRef]

33. Lin, R.; Lu, S.; Yang, A.; Shen, W.; Ren, J. Multi-criteria sustainability assessment and decision-making framework for hydrogen pathways prioritization: An extended ELECTRE method under hybrid information. Int. J. Hydrogen Energy 2021, 46, 13430-13445. [CrossRef]

34. Soumen, G.; Biswaranjan, M. Assessing coastal vulnerability to environmental hazards of Indian Sundarban delta using multicriteria decision-making approaches. Ocean Coast. Manag. 2021, 209, 105641.

35. Savun-Hekimoğlu, B.; Erbay, B.; Hekimoğlu, M.; Burak, S. Evaluation of water supply alternatives for Istanbul using forecasting and multi-criteria decision making methods. J. Clean. Prod. 2021, 287, 125080. [CrossRef]

36. Bertrand, M. Preference Functions and Thresholds. 14 June 2018. Available online: http:/ /www.promethee-gaia.net/assets/ preffunctions.pdf (accessed on 1 June 2021).

37. Kim, S.; Ko, W.; Bang, S. Analysis of Unit Process Cost for an Engineering-Scale Pyroprocess Facility Using a Process Costing Method in Korea. Energies 2015, 8, 8775-8797. [CrossRef] 